\title{
Simulation and parametric analysis of natural gas sweetening process: a case study of Missan Oil Field in Iraq
}

\author{
Jassim Mohammed Khanjar and Elham Omidbakhsh Amiri* \\ Department of Chemical Engineering, Faculty of Technology and Engineering, University of Mazandaran, Babolsar, P.O. Box 416, Iran
}

Received: 2 February 2021 / Accepted: 2 June 2021

\begin{abstract}
Gas sweetening is one of the important purification processes which is employed to remove acidic contaminants from natural gases prior to meet transport requirements and sale gas specifications. In this work, simulation and parametric studies of the natural gas processing plant of Missan Oil Company/Buzurgan Oil Field of Natural Gas Processing Plant (in Iraq) were considered. After simulation and validation of this plant, the effect of feed temperature and flow rate and solvent concentration were considered. Results show with increasing the feed temperature and flow rate, the amount of $\mathrm{H}_{2} \mathrm{~S}$ and $\mathrm{CO}_{2}$ in the sweet gas stream increases. Then, in the next step, the effect of mixture solvents was studied. Sulfolane-MDEA and MDEA-MEA were selected as a physical-chemical mixture solvent and chemical mixture solvent, respectively. The simulation results show that the solvent price and reboiler duty and cooling duty can be reduced by using a mixture solvent. However, the amount of $\mathrm{H}_{2} \mathrm{~S}$ and $\mathrm{CO}_{2}$ in the sweet gas can be affected by these solvents. The system by a chemical mixture solvent can better performance than other solvents.
\end{abstract}

\section{Introduction}

Natural gas is considered one of the best fuels. It is one of the non-renewable energy sources whose quantities decrease with the passage of time as a result of the massive use it. Natural gas can help to achieve some important energy goals. It can be used for economic development and environmental goals [1]. Natural gas is a complex mixture of hydrocarbons and non-hydrocarbons and consists mainly of methane $\left(\mathrm{CH}_{4}\right)$. It can also contain some undesirable impurities such as hydrogen sulfide $\left(\mathrm{H}_{2} \mathrm{~S}\right)$, Carbonyl sulfide (COS), and carbon disulfide $\left(\mathrm{CS}_{2}\right)$ and mercaptans $(\mathrm{R}-\mathrm{SH})$ in addition to the presence of varying percentages of nitrogen $\left(\mathrm{N}_{2}\right)$, carbon dioxide $\left(\mathrm{CO}_{2}\right)$, and others gases [2]. The Hydrogen sulfide $\left(\mathrm{H}_{2} \mathrm{~S}\right)$ gas is a highly toxic gas and a flammable, colorless gas. People can smell it at low levels and can cause poisoning death of people and livestock as well as highly corrosive rates to carbon steels in the transporting pipeline and process plant equipment of oil and natural gas where forms sulfuric acid with water. Also, the carbon dioxide gas is corrosive with water and reduces the heat energy value of natural gas when it burns as an energy source. On the other hand, carbon dioxide and hydrogen sulfide are inorganic gases that are strong hydrate formers. Natural gas hydrates are crystalline solid compounds formed when hydrogen-bonded water molecules form cages referred to as "host" and entrap or enclose molecules of some gases

* Corresponding author: e.omidbakhsh@umz.ac.ir and volatile liquids known as "guest molecules" [3]. Hydrate Formed and growth during transport of natural gas with a mixture of impurities of $\mathrm{CO}_{2}$ and $\mathrm{H}_{2} \mathrm{~S}$ are complex processes with various mechanisms and methods based on the kinetics and thermodynamics issues. So, removing the acid gases $\left(\mathrm{H}_{2} \mathrm{~S}\right.$ and $\left.\mathrm{CO}_{2}\right)$, heavy hydrocarbons, nitrogen, water, and other impurities is an obligatory case to produce a methane-rich gas. So, it can be used as fuel in various fields. This treatment process is representing one of the natural gas processing plant objectives [2].

There are two types of indirect acid gas removal [2]: adsorption and absorption. In the adsorption, the impurities of the gas are physically or chemically removed. In the absorption, the removal of acid gases is done by physical absorption using the physical solvents or by a chemical reaction with the acid gases using a chemical alkaline solvent or physical-chemical absorption by the mixture solvents. However, some new solvents for $\mathrm{CO}_{2}$ capture have been proposed for the improvement of the energy performance such as Biphasic Solvents and lipophilic amine solvents [4-6]. They have some potential advantages in terms of solvent regeneration and cyclic capacity. Extensive $\mathrm{CO}_{2}$ desorption is achieved at lower temperatures only slightly in excess of the lower critical phase transition temperatures, so, the waste heat for the solvent regeneration is reduced $[5,6]$. The improvements obtained using these types of solvents are based on its thermomorphic behavior. This phenomenon consists of the generation of two liquid phases after heating inside the reboiler [4]. 
In liquid-phase absorption processes, three categories of solvents are used: chemical solvents, physical solvents and hybrid solvents that contain both chemical and physical solvents. In processes using a chemical solvent, alkanol amines are usually used for the absorption of the acid gases. By reducing the pressure and/or using the high temperature, regeneration (desorption) can occur, and the acid gases are stripped from the solvent. In the physical solvent processes, there isn't any chemical reaction. Acid gas/organic sulfur components were removed based on physical absorption. The physical solvents are non-corrosive, requiring only carbon steel construction. Hybrid solvent processes (a mixture of a chemical and a physical solvent) combine the advantages of chemical and physical solvents. For removing organic sulfur compounds and COS, these solvents are a good choice. However, they have poor hydrocarbon selectivity [2].

In chemical solvents, amine is a famous solvent. The based component in amines is ammonia $\left(\mathrm{NH}_{3}\right)$. By replacing one or more of the hydrogen atoms with an organic hydrocarbon group, different kinds of amines are formed. An alkaline has the Portability to accept a proton $\left(\mathrm{H}^{+}\right)$ from water. By the reaction between water and a proton acceptor (an amine), the formation of hydroxide and an alkaline $\mathrm{pH}$ cause, which essential for gas sweetening with amines, and also contribute to reducing the corrosion in the pipelines [7]. Aqueous amine solutions are usually used to remove acidic gases such as carbon dioxide and hydrogen sulfide from gas streams in the natural gas, and refinery industries [8]. Alkanolamines are classified as follows [9]:

- Primary amines: such as monoethanolamine (MEA) and Di-Glycol Amine (DGA).

- Secondary amines: such as Di-Ethanol Amine (DEA) and Di-IsoPropanol Amine (DIPA).

- Tertiary amines: such as Tri-Ethanol Amine (TEA) and Methyl Di- EthanolAmine (MDEA).

The first type amines are stronger bases compared to other types and have higher tendencies to react with $\mathrm{H}_{2} \mathrm{~S}$ and $\mathrm{CO}_{2}$. In fact, in these chemical solvents, there are some equilibrium and kinetic reactions. For example, during this process using the MDEA solvent, equations (1)-(12) show the mechanism and overall reactions of $\mathrm{H}_{2} \mathrm{~S}$ and $\mathrm{CO}_{2}$ with (MDEA) solution. Equilibrium based and kinetic based reactions between aqueous MDEA solution and acid gases (hydrogen sulfide and carbon dioxide, respectively) have been occurred. The tertiary amine is instantaneously reacting with hydrogen sulfide but with a slower, and finite rate with carbon dioxide and it is considered pseudo-first-order reaction $[10,11]$

Ionization of $\mathrm{H}_{2} \mathrm{O}$ :

$$
2 \mathrm{H}_{2} \mathrm{O} \rightleftharpoons \mathrm{H}_{3} \mathrm{O}^{+}+\mathrm{OH}^{-} .
$$

Dissociation of $\mathrm{H}_{2} \mathrm{~S}$ :

$$
\mathrm{H}_{2} \mathrm{O}+\mathrm{H}_{2} \mathrm{~S} \rightleftharpoons \mathrm{H}_{3} \mathrm{O}^{+}+\mathrm{HS}^{-} \text {. }
$$

Hydroxylation of bisulfide:

$$
\mathrm{H}_{2} \mathrm{O}+\mathrm{HS}^{-} \rightleftharpoons \mathrm{H}_{3} \mathrm{O}^{+}+\mathrm{S}^{2-} \text {. }
$$

Dissociation of $\mathrm{CO}_{2}$ :

$$
2 \mathrm{H}_{2} \mathrm{O}+\mathrm{CO}_{2} \rightleftharpoons \mathrm{H}_{3} \mathrm{O}^{+}+\mathrm{HCO}_{3}^{-} .
$$

Dissociation of bicarbonate:

$$
\mathrm{H}_{2} \mathrm{O}+\mathrm{HCO}_{3}^{-} \rightleftharpoons \mathrm{H}_{3} \mathrm{O}^{+}+\mathrm{CO}_{3}^{2-} .
$$

Protonation of amine:

$$
\begin{gathered}
\mathrm{MDEA}+\mathrm{H}_{2} \mathrm{O} \rightleftharpoons \mathrm{OH}^{-}+\mathrm{MDEA}^{+}, \\
\mathrm{H}_{2} \mathrm{~S}+\mathrm{MDEA} \rightleftharpoons \mathrm{MDEA}^{+}+\mathrm{HS}^{-} .
\end{gathered}
$$

Phase equilibrium for acid gases is represented by Henry's Law:

$$
\begin{gathered}
\mathrm{Y}_{\mathrm{CO}_{2} \mathrm{P}}=\mathrm{H}_{\mathrm{CO}_{2}}\left[\mathrm{CO}_{2}\right], \\
\mathrm{Y}_{\mathrm{H}_{2} \mathrm{~S}} \mathrm{P}=\mathrm{H}_{\mathrm{H}_{2} \mathrm{~S}}\left[\mathrm{H}_{2} \mathrm{~S}\right] .
\end{gathered}
$$

There are two kinetic reactions: hydration of $\mathrm{CO}_{2}$ and formation of bicarbonate:

$$
\begin{gathered}
\mathrm{CO}_{2}+\mathrm{H}_{2} \mathrm{O} \rightarrow \mathrm{H}^{+}+\mathrm{HCO}_{3}^{-}, \\
\mathrm{CO}_{2}+\mathrm{OH}^{-} \rightarrow \mathrm{HCO}_{3}^{-} .
\end{gathered}
$$

The MDEA acts as a base catalyst for the hydrolysis of $\mathrm{CO}_{2}$ to bicarbonate:

$$
\mathrm{CO}_{2}+\mathrm{H}_{2} \mathrm{O}+\mathrm{MDEA} \rightarrow \mathrm{MDEAH}^{+}+\mathrm{HCO}_{3}^{-} .
$$

On the other hand, one of the usual physical solvents is sulfolane; Sulfolane is an organic chemical used for various industrial purposes such as natural gas processing, plastics, and electronics.

There are many studies about gas sweetening plants. Various viewpoints are considered in different studies such as economic evaluation [12], energy optimization [13, 14], and different solvents [15-18]. In this research, it was focused on the studies using different solvents.

In some studies, one single amine was used as a solvent such as Ghanbarabadi and Karimi Zad Gohari's work [15]. They studied the gas treatment unit in sarakhs refinery. MDEA was used as a solvent. By simulation using ASPEN HYSYS software, they studied the optimization of the concentration of MDEA. Also, the effect of the concentration of MDEA on some parameters was considered. Results showed that the tray temperature decreases by increasing the amine concentration. When the tower's temperature decreases, the lower flow of the solvent is needed to reach the standard characteristic of refined gas. Also, Zahid et al. [16] studied the simulation of this plant using Di Glycol Amine (DGA). By developing a steady-state model, they predicted the $\mathrm{CO}_{2}$ capture mechanism from the natural gas using DGA solvent. The Absorber and regenerator columns are the important equipment in this simulation. They focused on the energy analysis of this process and found the reboiler consumed the most energy. They found that around 0.46 GJ energy was required per ton of gas. Also, they considered the effect of some parameters, such as reboiler and absorption tower pressure. 
With increasing the reboiler and absorption tower pressure, $\mathrm{CO}_{2}$ concentration in the sweet gas decreases. In some other studies, mixture solvents were used. Ghanbarabadi and Khoshandam [9] studied the gas sweetening unit of Ilam gas using the mixed solvent (Sulfolane-MDEA- $\mathrm{H}_{2} \mathrm{O}$ ) and DGA, MDEA-AMP solvents. They studied the effect of different solvents on the $\mathrm{H}_{2} \mathrm{~S}$ and $\mathrm{CO}_{2}$ mole fraction in gas treating. They found that solvent MDEA + AMP is a good instance. In another work of mixture solvent, Kumar Sarker [17] studied the effect of some parameters such as concentration, circulation rate, pressure and temperature of the solvent. He used some amines as a single solvent (MEA, MDEA, DEA, DGA, DIPA), and some mixture amine solvents (DGA-MEA, DEA-MDEA and SULFOLANEMDEA). Results showed that all solvents except DGA react more quickly with $\mathrm{H}_{2} \mathrm{~S}$ than $\mathrm{CO}_{2}$. Also, DEA-MDEA showed the most effective sweetening efficiency. When only $\mathrm{H}_{2} \mathrm{~S}$ removal efficiency is considered, the performance of DGA solvent is better than others. However, the effect of different solvents was evaluated in different studies, but this subject needs to be considered more, especially using the mixture of chemical or chemical-physical solvents.

In this work, the gas sweetening plant of Missan Oil Company (MOC) (Missan Oil Fields Operation Division/ Buzurgan Oil Field), in the Missan city South of Iraq had been studied. The simulation was done using ASPEN HYSYS V10. The tertiary amines, specifically, MDEA, $45 \%$ wt. will be the basis of the treatment process. After the simulation in the base conditions, the effect of the feed temperature and flow rate, and amine concentration had been considered. In the next section, the effect of mixture solvents had been investigated. The primary amines, specifically, MEA, and physical solvents, specifically, Sulfolane will be used as secondary additives to form blends of solvents in the natural gas sweetening unit.

\section{Process description}

A process flow diagram of the amine unit of Buzurgan Oil Field (Missan Oil Company) is shown in Figure 1. Sour feed gas is filtered and cleaned of free liquids to prevent entries of contaminants in the amine system by an inlet filter separator. The separator gas is fed to the bottom of the amine absorber. Then, the gas goes upward through the column in intimate counter-current contact with the aqueous amine solution (lean amine solution), which is coming down from the top of the amine absorber column. In this column, with the reaction between the amine and the feed acid gas, the amine solution absorbs the acid gas. This chemical reaction is exothermic. It will raise the temperature of the gas. By removing the acid gas content by an aqueous amine solution, a rich amine solution provides at the bottom, and sweet gas will exist from the top of the absorption tower.

The amine solution with acid gas leaves the bottom of the absorber column. Then, it was sent to the amine flash drum. It is a three-phase separator designed for removing the dissolved gas and entrained liquid hydrocarbons. The flashed gas containing some $\mathrm{H}_{2} \mathrm{~S}$ is treated using a small packed section and recovered as fuel gas. The rich amine solution from the amine flash drum then passes through the rich amine filter. After that, the rich amine solution inlet to the rich amine/lean amine heat exchanger to preheat the rich solution to the regenerator, typically a plate and frame heat exchanger, to about $90-100{ }^{\circ} \mathrm{C}$. The high temperature of the regenerated solution (lean solution), which comes from the bottom of the regenerator tower and passes through the amine/amine exchanger, is used to heat the rich amine solution before entering the regenerator tower.

The rich amine leaves the amine/amine exchanger to enter the top of the regenerator tower and goes down to the counter current with acid vapor (impurities of the gases and water vapor are separated) and heated in the regenerator tower, stripped of acid gases and produce a hot lean amine. The reboiler is connected with the regenerator tower; it's a shell and tube heat exchanger to heating the rich amine solution to produce energy. So, the reverse chemical reaction is done to remove acid gas from the rich amine solution. The acid vapor generates for deleting the acid gas from the solution.

\section{Procedure of our simulation}

The first step in our simulation is setting up the fluid package which is combination of the component list as shown in Table 1 that will be used in the simulation and including all the components used in the process associated with a property package and that will be acid gas-chemical solvents package in our simulation. This package is based on the Electrolyte NRTL model (eNRTL) for electrolyte thermodynamics and Peng-Robinson Equation of State for vapor phase properties. Regression has been performed with available VLE and heat of absorption data for many amine solvents, including all major amine solvents used in the industry, such as: MDEA, MEA, Sulfolane-MDEA. Then, the feed sour natural gas stream of sulfur removal plant was defined with specific temperature, pressure and flow rate $\left(45^{\circ} \mathrm{C}, 4 \mathrm{MPag}, 71 \mathrm{Mmscfd}\right)$ with the feed composition based on mole fraction, is given in Table 1. This feed gas enters to the filter separator of feed gas (FIL-621101), vertical vessel with $90 \mathrm{kPa}$ of pressure drop for vapor outlet. Then, the vapor outlet enters from bottom of absorber tower, while lean amine solvent was defined as top feed of absorption tower. The lean amine solvent stream was defined (MDEA amine solution) with specific temperature, pressure and mass flow rate $\left(50.92{ }^{\circ} \mathrm{C}, 4298.24 \mathrm{MPag}\right.$, $117199.39 \mathrm{~kg} / \mathrm{h}$, respectively). $45 \%$ (by weight) MDEA \& $55 \% \mathrm{H}_{2} \mathrm{O}$ solution was used in this work.

Absorber tower (T-621101) consists from 24 ADV type trays. The pressure of first tray of absorber tower (from bottom) is $3900 \mathrm{kPa}$ and the pressure of the latter tray is $3800 \mathrm{kPa}$. The feed gas flows from bottom to top and contacts with the lean solution of amine solvent flows from top to bottom. The wet sweet gas off the sulfur removal unit at the top of absorber tower (T-621101) sent to the gas scrubber (V-621101) to separate the liquid droplets that purified gas brings out from the tower the wet sweet gas then enters to the user. The rich amine which has absorbed acid gas is 


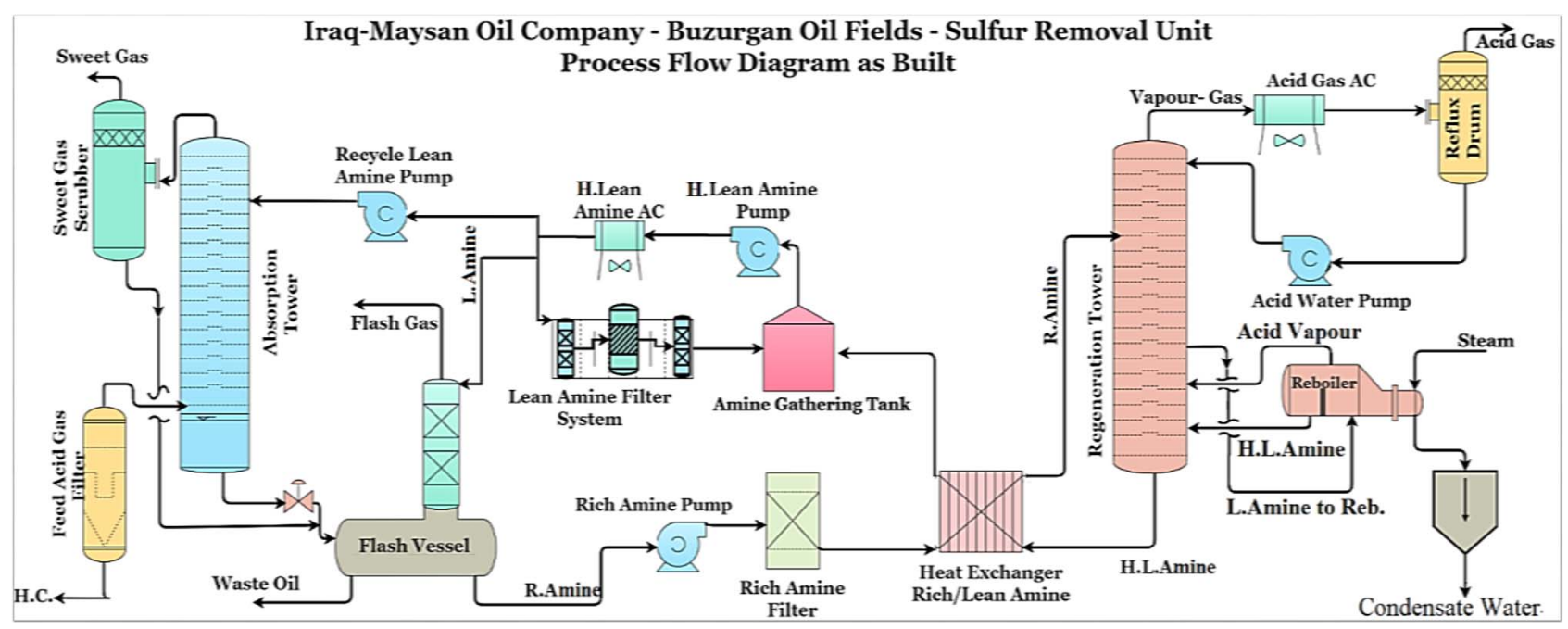

Fig. 1. Iraq-Missan Oil Company - Missan oil fields operation division/process flow diagram of Sulfur Removal Unit (SRU).

Table 1. The compositions of the feed gas.

\begin{tabular}{lc}
\hline Component & Content $(\mathrm{mol} \%)$ \\
\hline $\mathrm{N}_{2}$ & 0.492 \\
$\mathrm{C} 1$ & 58.864 \\
$\mathrm{C} 2$ & 15.086 \\
$\mathrm{C} 3$ & 10.247 \\
$\mathrm{i}-\mathrm{C} 4$ & 41.512 \\
$\mathrm{n}-\mathrm{C} 4$ & 43.611 \\
i-C5 & 0.765 \\
$\mathrm{n}-\mathrm{C} 5$ & 0.759 \\
$\mathrm{C} 6$ & 0.367 \\
$\mathrm{C} 7$ & 0.072 \\
$\mathrm{C} 8$ & 0.008 \\
$\mathrm{CO}$ & 5.105 \\
$\mathrm{H}_{2} \mathrm{~S}$ & 2.131 \\
$\mathrm{H}_{2} \mathrm{O}$ & 0.262 \\
\hline
\end{tabular}

out from the bottom of amine absorber (T-621101). After the pressure adjustment by the liquid level control valve at the bottom of amine absorber (T-621101), it enters the rich amine flash vessel (V-621102, operating temperature: $67{ }^{\circ} \mathrm{C}$, operating pressure: $0.2 \mathrm{MPag}$ ). Part of dissolved hydrocarbon gas was flashed off the solution in the vessel, with dissolved condensate in the solution is separated from the solution in the flash vessel and skimmed out of the solution system. Flash gas with flowing during the packed tower (with four trays of pall ring) from bottom to top contacts with the lean amine stream (temperature: $50{ }^{\circ} \mathrm{C}$, pressure: $615.53 \mathrm{kPag}$ ) flowing from top to bottom, with most of $\mathrm{H}_{2} \mathrm{~S}$ gas separated from the flash gas. Rich amine pumped by rich amine pump (P-621106) out of the bottom of rich amine flash vessel via the liquid level control valve exchanges heat with the hot lean amine coming from the bottom of amine regenerator (T-621103) via the lean/rich solution heat exchanger (E-621101, pressure drop of tube and shell side $=15.58$ and $10.21 \mathrm{kPa}$ respectively). Then, the temperature of outlet rich amine stream from heat exchanger (E-621101) is rising to about $96.05{ }^{\circ} \mathrm{C}$ after that enters into the amine regenerator tower (T-621103).

The amine regenerator tower (T-621103) with $24 \mathrm{ADV}$ type trays (top \& bottom temperature $=108^{\circ} \mathrm{C}$ and $123^{\circ} \mathrm{C}$, respectively and top \& bottom pressure $=0.24$ and 0.25 MPag, respectively) flowing from top to bottom and contacting with the steam continuous flowing from bottom to top in a count-current way inside the regeneration tower, by which, the hydrocarbons, $\mathrm{H}_{2} \mathrm{~S}$ and $\mathrm{CO}_{2}$ are stripped out of the rich solution. The hot lean amine is sent to the amine make up vessel (MAKEUP-100) and mixed with fresh amine solvent solution. Due to the water imbalance of this section, make-up water must be fed to the system continuously in order to maintain the solution concentration. The make-up water is supplied by adding demineralized water to acid water pipeline in MAKEUP100. Then, the flow is pumped by a hot lean amine pump (P-621102) until the pressure outlet reaches to $800 \mathrm{kPa}$. Then, it is sent to a hot lean amine air cooler (AC-621101, temperature $=50^{\circ} \mathrm{C}$, pressure: $0.75 \mathrm{MPag}$ ). The outlet lean amine stream from AC-621101 splits into two branches, one of them pumped by lean amine recycle pump (P-621101) to absorber tower (T-621101), to complete the circulation of the whole solution system. And another branch sent to the amine packed tower on the flash vessel. In the outlet of the top of amine regeneration tower T-621103, the acid gas is cooled to $45^{\circ} \mathrm{C}$ by acid air cooler (AC-621102). After the acid gas air cooler, the acid gas enters the amine regeneration tower reflux vessel $\left(\mathrm{V}-621103\right.$, temperature $=45^{\circ} \mathrm{C}$, Pressure $=68 \mathrm{kPa}$ ) to separate acidic condensate water. Then, the acid gas is sent to the sulfur recovery unit. The separated acidic condensate water is pumped by acid water reflux pump $(\mathrm{P}-621103$, pressure outlet $=243 \mathrm{kPa})$ to the top of the amine regenerator (T-621103) at 24 tray position for refluxing the acid gas removed which goes into sulfur 


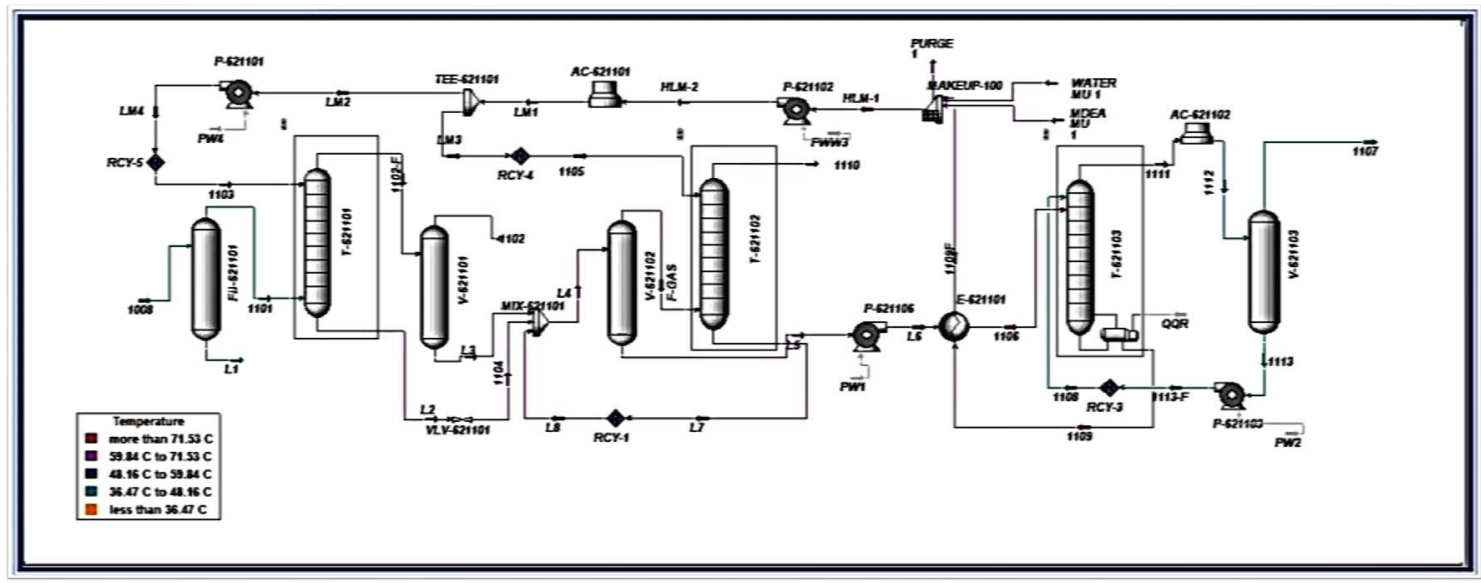

Fig. 2. The final simulation of MOC-IRAQ-sulfur removal unit, Buzurgan oil field.

Table 2. Comparison between the industrial data and this simulation for stream 1107 .

\begin{tabular}{lccc}
\hline Parameter & Industrial data & This work & Error $(\%)$ \\
\hline Mass flow rate $(\mathrm{kg} / \mathrm{h})$ & 7835.92 & 7955.82 & 1.53 \\
$\mathrm{CO}_{2}($ wt.\%) & 56.985 & 51.43 & 9.748 \\
$\mathrm{H}_{2} \mathrm{~S}($ wt.\%) & 37.11 & 34.04 & 8.272 \\
\hline
\end{tabular}

recovery unit or the flare system. Figure 2 shows the final simulation of this unit.

\section{Results and discussion}

\subsection{Validation of simulation}

In this section, as first step, the results of our simulation were compared with the industrial data (Missan Oil Company/Buzurgan Oil Field of Natural Gas Processing Plant) for validation of simulation. For this comparison, the operating conditions and $\mathrm{H}_{2} \mathrm{~S}$ and $\mathrm{CO}_{2}$ amount of some streams were considered. As a sample, this comparison for stream 1107 is reported in Table 2. The results show that the average error is less than 10 percent. So, it can be said that there is a good agreement between these data.

\subsection{Effect of operating conditions}

After the validation of our simulation, in this section, the effect of the operating conditions on the amount of $\mathrm{H}_{2} \mathrm{~S}$ and $\mathrm{CO}_{2}$ in the sweet gas was considered. The feed gas flow rate and temperature, and lean amine concentration are operating conditions in this section. In all of the considerations of this section, MDEA (45\% wt.) was used as a solvent.

Figure 3 shows the variation of the amount of $\mathrm{H}_{2} \mathrm{~S}$ and $\mathrm{CO}_{2}$ in the sweet gas versus the feed gas flow rate. As is observed in Figure 3, the $\mathrm{H}_{2} \mathrm{~S}$ and $\mathrm{CO}_{2}$ impurities concentration increases rapidly with increasing feed flow rate.
The increasing in the gas/liquid flow rate ratio (with increasing gas feed flow) causes an increase in the gas velocity, which reduces the chances of reactions between the acid gas molecules and the solvent molecules due to decreased contact time between the acid gases $\left(\mathrm{H}_{2} \mathrm{~S} \& \mathrm{CO}_{2}\right)$ and liquid phases (or amine solution), and thus limited the reactions of the acid gases with an amine solution. On the other hand, the increasing in the gas flowrate means an increasing number of $\mathrm{H}_{2} \mathrm{~S}$ and $\mathrm{CO}_{2}$ gas molecules at the expense of the number of absorbent molecules that have become insufficient to react with $\mathrm{H}_{2} \mathrm{~S}$ and $\mathrm{CO}_{2}$ gases inside an absorption tower, and thus increasing the number of acid gases molecules fugitive with sweet gas stream without being removed by interacting with the amine absorbent molecules. So, increasing the gas flow rate reduces the removal performance of both $\mathrm{CO}_{2}$ and $\mathrm{H}_{2} \mathrm{~S}$ gases [19].

Feed gas temperature is another operating condition that was considered in this work and in this section. Figure 4 shows the effect of feed gas temperature on the amount of $\mathrm{H}_{2} \mathrm{~S}$ and $\mathrm{CO}_{2}$ in the sweet gas. Results show that as the temperature of feed gas increases from $35{ }^{\circ} \mathrm{C}$ to $55^{\circ} \mathrm{C}$, the $\mathrm{H}_{2} \mathrm{~S}$ and $\mathrm{CO}_{2}$ contents increase in the sweet gas stream. Acid gases $\left(\mathrm{H}_{2} \mathrm{~S}\right.$ and $\left.\mathrm{CO}_{2}\right)$ have more volatility in higher temperatures. So, with increasing the feed gas temperature, the absorption rate with amine solution reduces.

As shown in Figure 5, with increasing the aqueous MDEA concentration from 40 wt. $\%$ to $50 \%, \mathrm{H}_{2} \mathrm{~S}$ content in the sweet gas stream decreases. Based on the Le Chatelier's principle, by adding the reactants in a system, the equilibrium will shift to the right to produce more products. So, the absorption rate of acid gases increases. Although, the selectivity of $\mathrm{H}_{2} \mathrm{~S}$ over $\mathrm{CO}_{2}$ acid gas with 

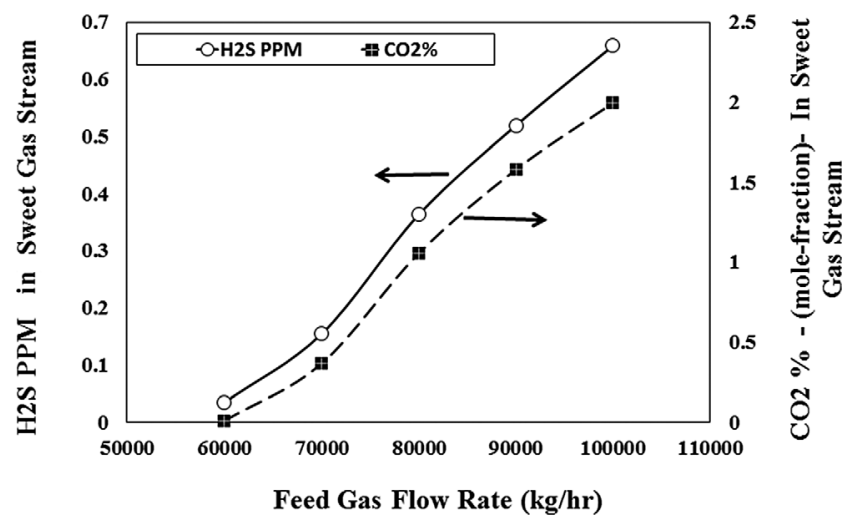

Fig. 3. Effect of feed gas flow rate on the amount of $\mathrm{H}_{2} \mathrm{~S}$ and $\mathrm{CO}_{2}$ in sweet gas stream (feed gas temperature $=45^{\circ} \mathrm{C}, \mathrm{MDEA}$ concentration $=45 \%)$.

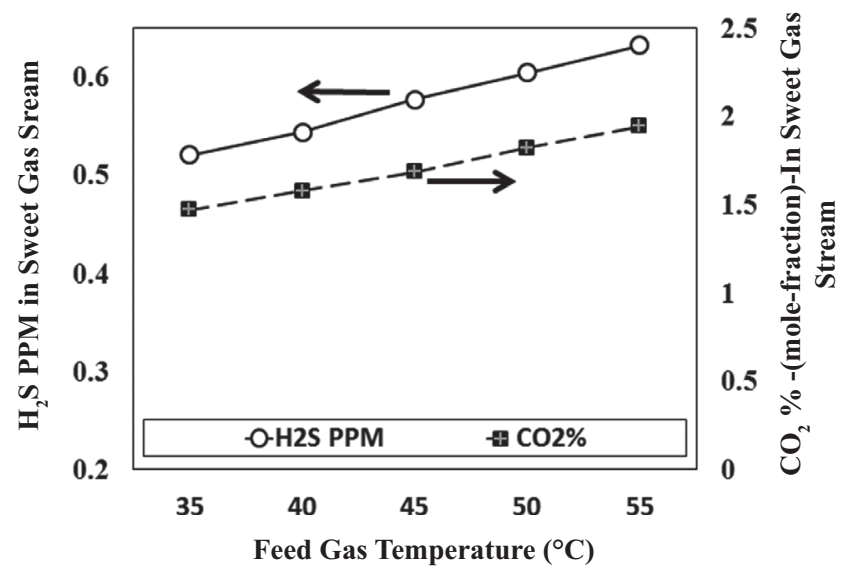

Fig. 4. Effect of feed gas temperature on the amount of $\mathrm{H}_{2} \mathrm{~S}$ and $\mathrm{CO}_{2}$ in sweet gas stream (feed gas flow rate $=92745 \mathrm{~kg} / \mathrm{h}$, MDEA concentration $=45 \%$ ).

MDEA solvent, essentially causes more $\mathrm{H}_{2} \mathrm{~S}$ removal while only a portion of $\mathrm{CO}_{2}$ is removed enriching the acid gas feed.

According to the local restrictions, it is hoped that the amount of $\mathrm{H}_{2} \mathrm{~S}$ and $\mathrm{CO}_{2}$ in the sweet gas be less than 7.5 ppm and $2.5 \%$ (mole), respectively. As it can be seen, in above considerations, for the effect of operating conditions, it is established.

\subsection{Effect of solvent type}

In this section, the simulation with a mixture solvent was considered and then, the results were compared with the MDEA solvent (as a single solvent). Also, two types of the mixture solvent were considered: the physical-chemical mixture solvent and chemical mixture solvent.

\subsubsection{Physical-chemical mixture solvent}

Sulfolane as a physical solvent (20\% wt.) mixed with MDEA as a chemical solvent (45\% wt.) was considered and used for this section. The solvents blend is made up

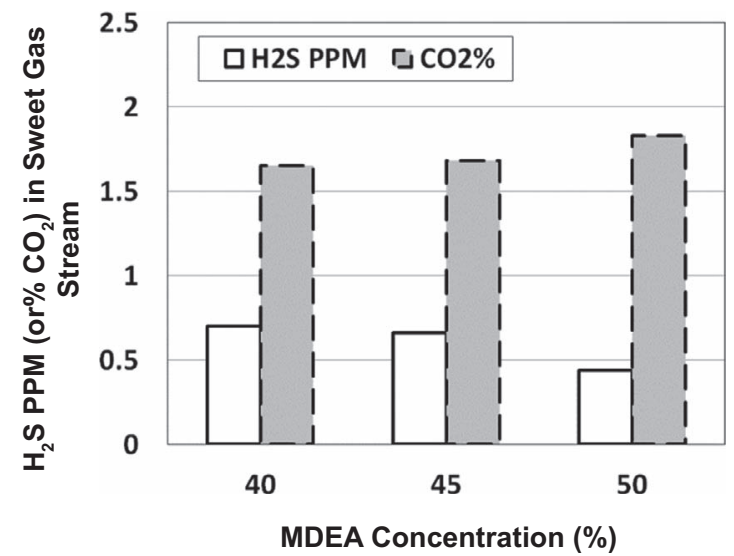

Fig. 5. Effect of Lean Amin concentration on the amount of $\mathrm{H}_{2} \mathrm{~S}$ and $\mathrm{CO}_{2}$ in sweet gas stream (feed gas flow rate $=92745 \mathrm{~kg} / \mathrm{h}$, feed gas temperature $\left.=45^{\circ} \mathrm{C}\right)$.

of Sulfolane, MDEA and water and called Sulfinol-M. The reaction with MDEA and the physical solubility of acid gases in this solvent can help to remove acid gases. Figure 6 shows the effect of feed gas temperature on the amount of $\mathrm{H}_{2} \mathrm{~S}$ and $\mathrm{CO}_{2}$ with this mixture solvent. Such as the previous section (MDEA solvent used as a single solvent), results show that with increasing the temperature, these amounts increase. The reason of this happen in this system is the same reason as mentioned comments. Also, the amount of $\mathrm{H}_{2} \mathrm{~S}$ and $\mathrm{CO}_{2}$ in the sweet gas stream in the system with MDEA solvent is lower than the system with the mixture (MDEA + Sulfolane) solvent. In fact, with changing the composition of the solvent, by adding sulfolane, the amount of water in the solvent solution decreases. $\mathrm{CO}_{2}$ reaction with amine occurs in the aqueous solution [20], so, with reducing the amount of water, the reaction rate decreases and the absorption of $\mathrm{CO}_{2}$ decreases. As result, the amount of acid gases increases.

Also based on the local restrictions (the amount of $\mathrm{H}_{2} \mathrm{~S}$ and $\mathrm{CO}_{2}$ in the sweet gas be less than $7.5 \mathrm{ppm}$ and $2.5 \%$ (mole), respectively), results show in some temperatures with this solvent, these criteria aren't established. Red colored left right arrow shows the criteria for the amount of $\mathrm{H}_{2} \mathrm{~S}$ and $\mathrm{CO}_{2}$.

Based on the results of Figure 6 and its interpretation, in the next step, the amount of water in the solution solvent remains constant and the amount of MDEA and sulfolane is changed as the sum of these amounts remains constant, and there isn't any change in the water amount in the solution. So, the new mixture solvent (MDEA 30\% and Sulfolane $15 \%$ ) was used in simulation, and its results were compared with results of the system by MDEA $45 \%$ solvent in Figure 7. Results show that the amount of $\mathrm{H}_{2} \mathrm{~S}$ in the system with MDEA solvent is much higher than a mixture solvent. However, the amount of $\mathrm{CO}_{2}$ in the system with MDEA solvent is less than a mixture solvent (but, in both systems, the amount of $\mathrm{H}_{2} \mathrm{~S}$ and $\mathrm{CO}_{2}$ is less than the criteria. Red colored left right arrow shows the criteria for the amount of $\mathrm{CO}_{2}$ ). In the system with a mixture solvent, the amount of MDEA in the solvent decreases, so, the reaction rate between amine and $\mathrm{CO}_{2}$ decreases and the amount 

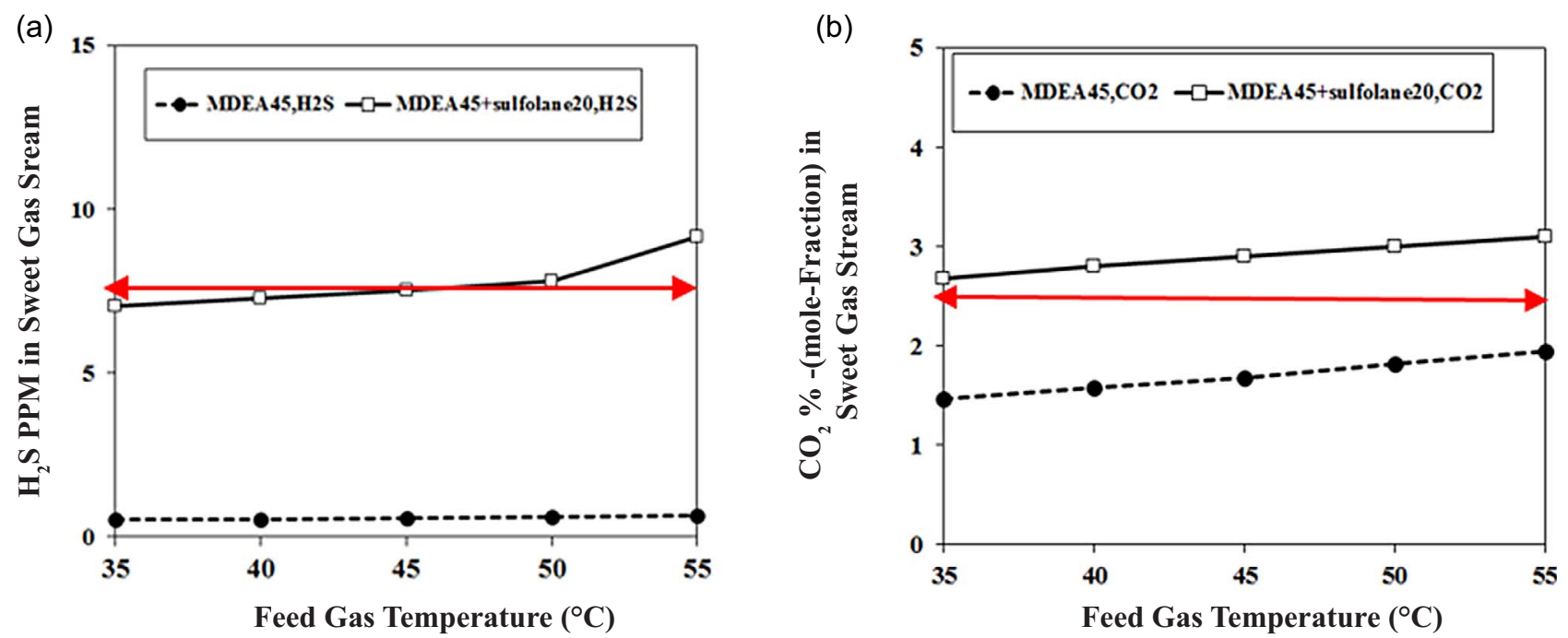

Fig. 6. Effect of Feed gas temperature and solvent type (MDEA as a single solvent and MDEA $45+$ Sulfolane 20 as mixture solvent) on the amount of (a) $\mathrm{H}_{2} \mathrm{~S}$ and (b) $\mathrm{CO}_{2}$ in sweet gas stream.
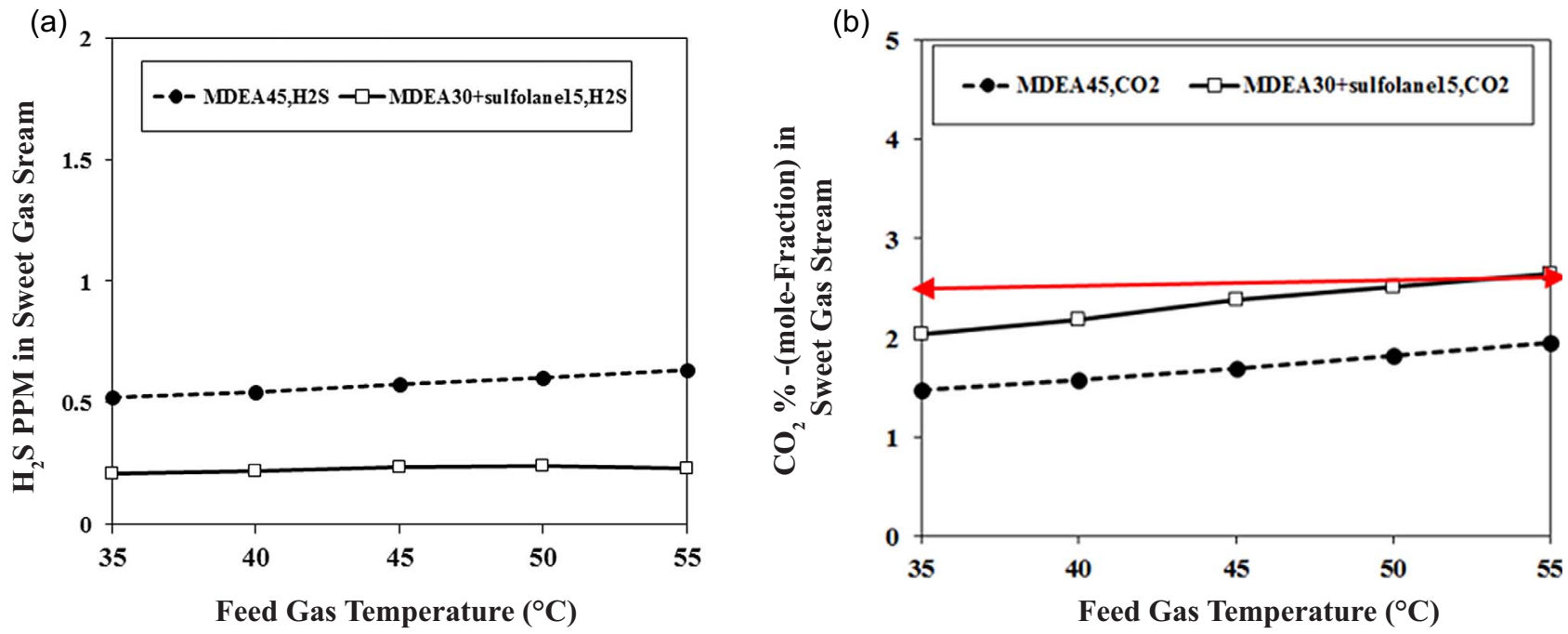

Fig. 7. Effect of feed gas temperature and solvent type (with new composition of MDEA $30+$ Sulfolane 15 as a mixture solvent) on the amount of (a) $\mathrm{H}_{2} \mathrm{~S}$ and (b) $\mathrm{CO}_{2}$ in sweet gas stream.

of $\mathrm{CO}_{2}$ in the sweet gas increases. About $\mathrm{H}_{2} \mathrm{~S}$ results, it can be found that the adding sulfolane as a physical solvent has an effective impact on the solubility of $\mathrm{H}_{2} \mathrm{~S}$, so, more $\mathrm{H}_{2} \mathrm{~S}$ removed, and, the amount of $\mathrm{H}_{2} \mathrm{~S}$ in this system with mixture solvent is lower than the MDEA solvent.

Figure 8 shows the comparison of the solvent price and energy consumption of two above systems. In Figure 8a, the solvent price was calculated based on the amount of MDEA and sulfolane in each solvent solution. The price of MDEA and sulfolane is found from Alfa Aesar Chemical Company. ${ }^{1}$ From Figure 8 a, it can be found that the solvent price in the system with MDEA $30 \%+$ sulfolane $15 \%$ is less

\footnotetext{
${ }^{1}$ https://www.alfa.com
}

than the system with MDEA 45\% solvent. With decreasing the MDEA amount in the mixture solvent, the price of MDEA decreases; however, the sulfolane price added to the solvent price. Finally, the solvent price decreases about $10 \%$.

The energy consumption of the systems with these solvents was considered (Fig. 8b). The reboiler duty of the regeneration tower and the air cooling for cooling solvent were accounted for energy consumption. The reboiler duty of the regeneration tower in both systems is near to each other. Also, the duty of cooling of lean amine (or solvent) in the system with MDEA 30\% + sulfolane $15 \%$ is less than the system with MDEA $45 \%$ solvent. With decreasing the MDEA concentration in the mixture solvent (MDEA 
(a)

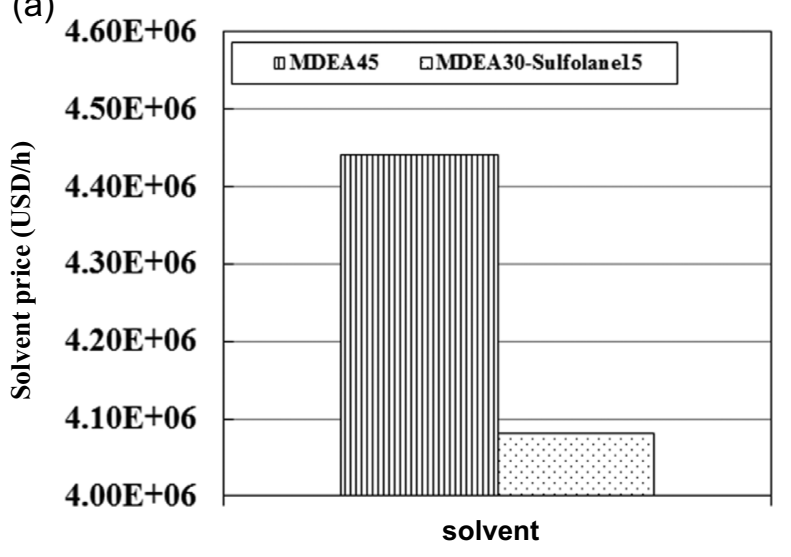

(b)

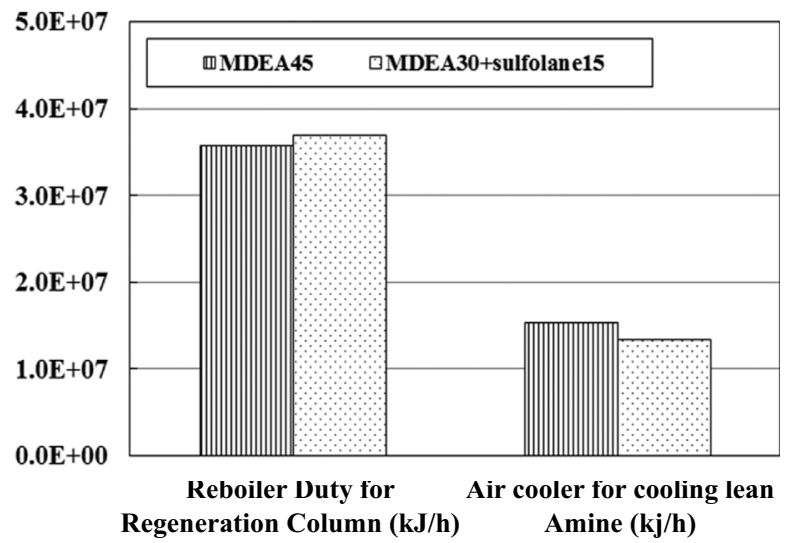

Fig. 8. (a) Solvent price and (b) energy consumption of two systems: a system with MDEA solvent and another system with MDEA + Sulfolane solvent.

(a)

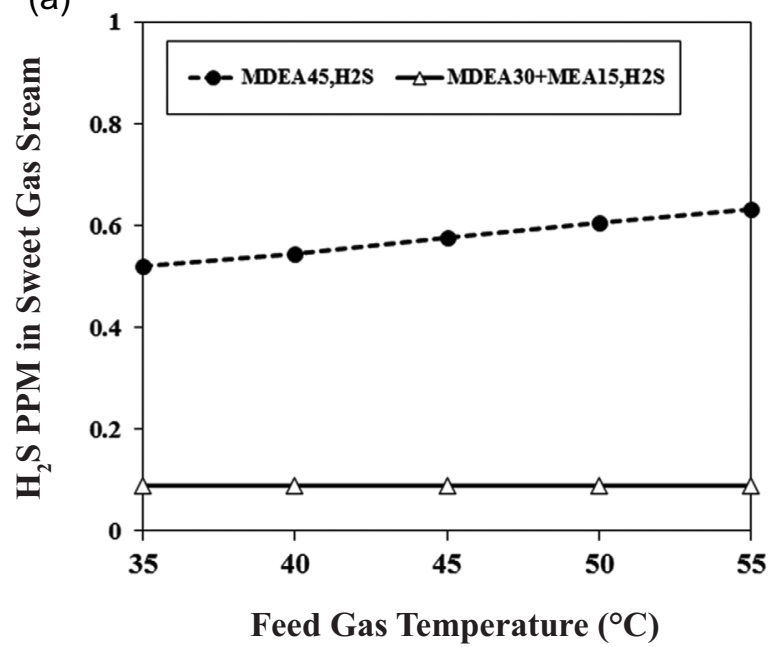

(b)

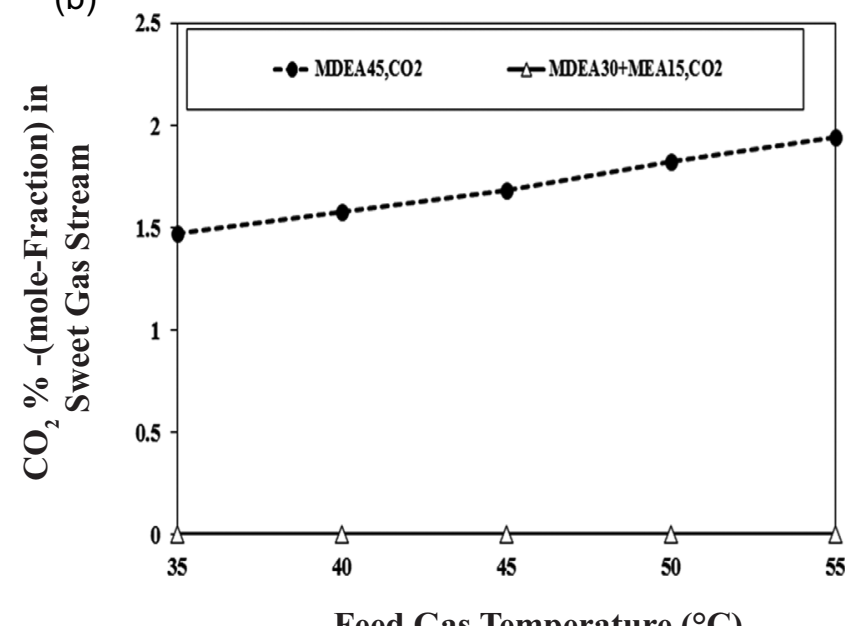

Fig. 9. Effect of feed gas temperature and solvent type (with a mixture chemical solvent, MDEA $30+$ MEA 15) on the amount of (a) $\mathrm{H}_{2} \mathrm{~S}$ and (b) $\mathrm{CO}_{2}$ in sweet gas stream.

$30 \%+$ sulfolane $15 \%$ ), the reaction rate between amine and $\mathrm{CO}_{2}$ decreases. This reaction is exothermic, so, with decreasing the reaction rate, the rising temperature is less than another one, and the duty for cooling is much lower [20].

\subsubsection{Chemical mixture solvent}

In this section, the mixture solvent with two chemical solvents was used. MDEA and MEA are chemical solvents; they have different properties that show their different behaviors in dealing with the removal of acid gases. MDEA-MEA solvents blend $(30-15 \%)$ was used as a solvent in this process. Figure 9 shows that when the feed temperature increases from $35{ }^{\circ} \mathrm{C}$ to $55{ }^{\circ} \mathrm{C}$, the $\mathrm{H}_{2} \mathrm{~S}$ and $\mathrm{CO}_{2}$ contents increase in the sweet gas stream. In general, it is known that the reaction of acid gases with the solutions of amine in the absorption tower is balanced exothermic reactions (forward reaction) and the capacity of absorption is more appreciated at the lower temperature [21].

Based on the results of Figure 9, the amount of $\mathrm{H}_{2} \mathrm{~S}$ and $\mathrm{CO}_{2}$ in the system with MDEA 30\% + MEA $15 \%$ is less than the system with MDEA $45 \%$ solvent. However, in both systems, the amount of $\mathrm{H}_{2} \mathrm{~S}$ and $\mathrm{CO}_{2}$ is less than the criteria. With adding MEA solvent, both chemical solvents react with acid gases. However, MEA solvent will react with $\mathrm{H}_{2} \mathrm{~S}$ and $\mathrm{CO}_{2}$ non-selectively. So, it can be found a mixture solvent of MDEA and MEA can be removed more than only MDEA solvent. This finding was presented in some previous researches [22, 23].

Figure 10a shows the comparison of the solvent of two above systems. The price of MEA is found from Footnote 1. It can be found that the solvent price in the system with MDEA 30\% + MEA 15\% solvent is less than another system (about 25\%). The energy consumption of the 
(a)

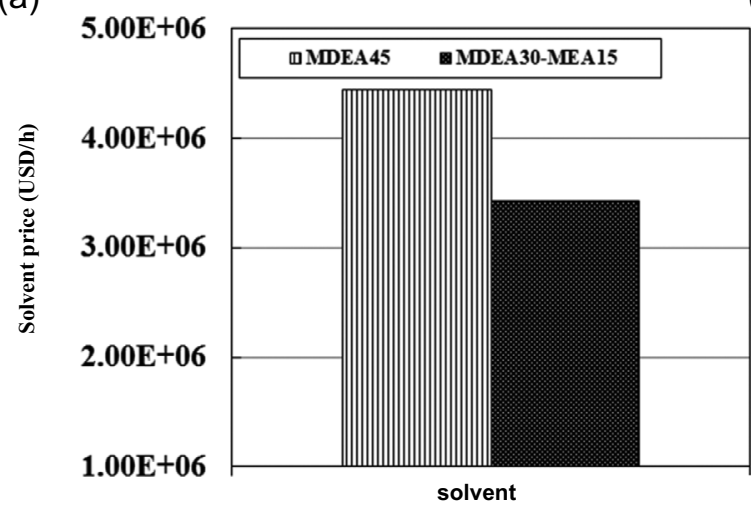

(b)

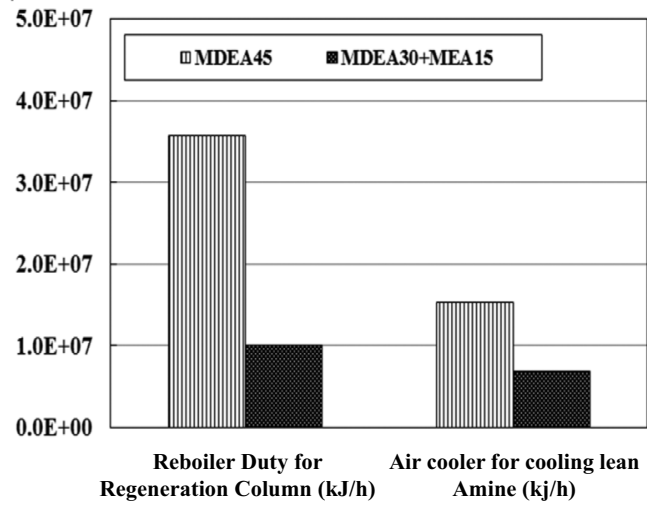

Fig. 10. (a) Solvent price and (b) energy consumption of two systems: a system with MDEA solvent and another system with MDEA + MEA solvent.

systems with these solvents is shown in Figure 10b. The reboiler duty of the regeneration tower and the air cooling for cooling solvent were accounted for energy consumption. The reboiler duty and the cooling duty in the system with MDEA 30\% + MEA 15\% solvent are much lower than in another system. Chemical reaction with MDEA solvent is more exothermic than the reaction with MEA solvent. Also, in a mixture solvent (MDEA 30\% + MEA 15\%), the concentration of MDEA is lower than MDEA 45\% solvent, so, the temperature didn't raise much, so the high cooling duty didn't need.

\section{Conclusion}

The simulation process was carried out using ASPEN HYSYS software V10, for the purpose of studying and evaluating the performance of the sour natural gas sweetening plant in the absorption and removal of acidic gases in sulfur removal unit of Missan natural gas processing plant in Missan Oil Company (in Iraq). Three types of different solvents (single chemical solvent (MDEA), chemical solvent blend (MDEA-MEA), and physical-chemical solvent blend (Sulfolane-MDEA)) were considered. The results can be found that with increasing of the feed flow rate and temperature, the amount of $\mathrm{H}_{2} \mathrm{~S}$ and $\mathrm{CO}_{2}$ in the sweet gas stream increases. So, the removal performance of both $\mathrm{CO}_{2}$ and $\mathrm{H}_{2} \mathrm{~S}$ gases decreases. Also, with increasing the aqueous MDEA concentration from 40 wt. $\%$ to $50 \%, \mathrm{H}_{2} \mathrm{~S}$ content in the sweet gas stream decreases. In the consideration of the effect of the physical-chemical solvent, results show that the amount of $\mathrm{H}_{2} \mathrm{~S}$ in the system with MDEA solvent is much higher than MDEA 30\% + Sulfolane 15\% solvent. However, the amount of $\mathrm{CO}_{2}$ in the system with MDEA solvent is less than mixture solvent. In addition, the solvent price in system with MDEA $30 \%+$ sulfolane $15 \%$ is less than the system with MDEA $45 \%$ solvent about $10 \%$. The duty of cooling of solvent in system with MDEA $30 \%+$ sulfolane $15 \%$ is less than the system with MDEA $45 \%$ solvent. On the other hand, the amount of $\mathrm{H}_{2} \mathrm{~S}$ and $\mathrm{CO}_{2}$ in the system with MDEA $30 \%+$ MEA $15 \%$ is less than the system with MDEA $45 \%$ solvent. Also, the solvent price in system with MDEA $30 \%+$ MEA $15 \%$ solvent is less than another system about $25 \%$.

Acknowledgments. Authors would like to acknowledge the natural gas processing plant operators of Missan Oil Company (Buzurgan Oil Field in Iraq) for the provided information.

\section{References}

1 Mokhatab S., Poe W.A. (2012) Handbook of natural gas transmission and processing, 2nd edn., Gulf Professional Publishing, Oxford, UK.

2 Mokhatab S., Poe W.A., Mak J.Y. (2019) Handbook of natural gas transmission and processing: Principles and practices, 4th edn., Gulf Professional Publishing, Oxford, UK.

3 Aromada S.A., Kvamme B. (2019) Impacts of $\mathrm{CO}_{2}$ and $\mathrm{H}_{2} \mathrm{~S}$ on the risk of hydrate formation during pipeline transport of natural gas, Front. Chem. Sci. Eng. 13, 616-627.

4 Vega F., Cano M., Camino S., Fernández L.M.G., Portillo E., Benito Navarrete B. (2018) Solvents for carbon dioxide capture, in: Karamé I., Shaya J., Srour H. (eds), Carbon dioxide chemistry, capture and oil recovery, IntechOpen, London, UK. https://doi.org/10.5772/intechopen.71443.

5 Xu Zh, Wang Sh, Qi G., Liu J., Zhao B., Chen Ch. (2014) $\mathrm{CO}_{2}$ absorption by biphasic solvents: Comparison with lower phase alone, Oil Gas Sci. Technol. - Rev. IFP Energies nouvelles 69, 5, 851-864.

6 Zhang J., Agar D.W., Zhang X., Geuzebroek F. (2011) $\mathrm{CO}_{2}$ absorption in biphasic solvents with enhanced low temperature solvent regeneration, Energy Procedia 4, 67-74.

7 Hansen H. (2014) Amines as gas sweetening agents, Master Thesis, Aalborg University, Aalborg, Denmark.

8 Benamor A., Kheireddine Aroua M., Aroussi A. (2012) Kinetics of $\mathrm{CO}_{2}$ absorption into aqueous blends of diethanolamine and mthyldiethanolamine, in: Proceedings of the $3 \mathrm{rd}$ International Gas Processing Symposium, Qatar, 5-7 March 2012.

9 Ghanbarabadi H., Khoshandam B. (2015) Simulation and comparison of Sulfinol solvent performance with Amine solvents in removing sulfur compounds and acid gases from natural sour gas, J. Nat. Gas Sci. Eng. 22, 415-420. 
10 Jassim M. (2016) Sensitivity analyses and optimization of a gas sweetening plant for hydrogen sulfide and carbon dioxide capture using methyldiethanolamine solutions, J. Nat. Gas Sci. Eng. 36, 175-183.

11 Patil P., Malik Z., Jobson M. (2006) Prediction of $\mathrm{CO}_{2}$ and $\mathrm{H}_{2} \mathrm{~S}$ solubility in aqueous MDEA solutions using an extended Kent and Eisenberg model, Inst. Chem. Eng. (IChemE), Symp. Ser. 152, 498-510.

12 Kazemi A., Malayeri M., Gharibi Kharaji A., Shariati A. (2014) Feasibility study, simulation and economical evaluation of natural gas sweetening processes - Part 1: A case study on a low capacity plant in Iran, J. Nat. Gas Sci. Eng. 20, 16-22.

13 Gutierrez J.P., Tarifa E., Erdmann E. (2018) Steady-state energy optimization and transition assessment in a process of $\mathrm{CO}_{2}$ absorption from natural gas, Energy 159, 1016-1023.

14 Gutierrez J.P., Liliana Ale Ruiz E., Erdmann E. (2017) Energy requirements, GHG emissions and investment costs in natural gas sweetening processes, J. Nat. Gas Sci. Eng. 38, 187-194.

15 Ghanbarabadi H., Karimi Zad Gohari F. (2014) Optimization of MDEA concentration in flow of input solvent to the absorption tower and its effect on the performance of other processing facilities of gas treatment unit in Sarakhs refinery, J. Nat. Gas Sci. Eng. 20, 208-213.

16 Zahid U., Al Rowaili F.N., Ayodeji M.K., Ahmed U. (2017) Simulation and parametric analysis of $\mathrm{CO}_{2}$ capture from natural gasusing diglycolamine, Int. J. Greenhouse Gas Control 57, 42-51.

17 Kumar Sarker N. (2016) Theoretical effect of concentration, circulation rate, stages, pressure and temperature of single amine and amine mixture solvents on gas sweetening performance, Egypt. J. Pet. 25, 343-354.

18 Emmanuel Akinola T., Oko E., Wang M. (2019) Study of $\mathrm{CO}_{2}$ removal in natural gas process using mixture of ionic liquid and MEA through process simulation, Fuel 236, 135-146.

19 Mirfendereski M., Mohammadi T. (2017) Investigation of $\mathrm{H}_{2} \mathrm{~S}$ and $\mathrm{CO}_{2}$ removal from gas streams using hollow fiber membrane gas-liquid contactors, Chem. Biochem. Eng. Q. 31, 2, 139-144.

20 Nejat T., Movasati A., Wood D.A., Ghanbarabadi H. (2018) Simulated exergy and energy performance comparison of physical-chemical and chemical solvents in a sour gas treatment plant, Chem. Eng. Res. Des. 133, 40-54.

21 Petrucci R.H., Harwood W.S., Herring G.E., Madura J. (2006) General chemistry: Principles and modern application, 9th edn., Pearson/Prentice Hall, Hoboken, NJ.

22 Abdulrahman R.K., Sebastine I.M. (2013) Natural gas sweetening process simulation and optimization: A case study of Khurmala field in Iraqi Kurdistan region, J. Nat. Gas Sci. Eng. 14, 116-120.

23 Abdel-Aal K., Aggour M. (2003) Petroleum and gas field processing, CRC Press, New York. 